\title{
DA IMAGEM ÀS IMAGENS EM MOVIMENTO o narrativo na Invenção de Orfeu de Jorge de Lima
}

\section{Fábio de Souza Andrade}

Resumo A leitura da Invenção de Orfeu, súmula do percurso poético de Jorge de Lima, implica a consideração simultânea de uma série de questões: o engajamento modernista do poeta, o diálogo do poema com a tradição épica brasileira, a mescla de épico e lírico que marca o poema longo na literatura moderna. Este artigo propõe um caminho crítico na interpretação da Invenção de Orfeu que, ao lado de reconhecer a importância de sua ousadia imagética, aborde os aspectos narrativos da obra.

Palavras-chave Jorge de Lima, Invenção de Orfeu, Modernismo brasileiro.

Abstract The reading of Invenção de Orfeu, summary of Jorge de Lima's poetic journey, implies the simultaneous consideration of a series of topics: the poet's partake in Modernism, the poem's dialogue with the Brazilian epic tradition, the mixture of epic and lyric that characterizes the long poem in modern literature. This paper proposes a critical orientation in the analysis of Invenção de Orfeu, that besides recognizing the importance of its imagetic daring also intends to bring forth the narrative aspects of the poem. Keywords Jorge de Lima, Invenção de Orfeu, Brazilian modernism. 


\section{A imagem hermética: a Invenção de Orfeu e seu lugar}

Cada vez que a obra de Jorge de Lima vem à baila, traz consigo uma série de questões espinhosas a serem enfrentadas por aquele que se propõe a tornar mais nítida a compreensão deste escritor plural e de longa história criativa, transitando por artes e estilos diversos. Todo estudo sobre o poeta e romancista alagoano acaba forçado a optar entre uma abordagem particularizante, destacando e realçando altos e baixos de algum dos momentos que compõem sua fisionomia, e uma aproximação unitária, em busca de um projeto literário, um fio persistente a alinhavar as fases e faces do autor de Mira-Celi

Os percursos biográfico e criativo de Jorge de Lima se espelham em sua extensão e complexidade. $O$ criador dividiu-se entre a pintura, a fotomontagem de inspiração surrealista, o romance, mas brilhou acima de tudo na poesia. O homem dividiu-se entre a medicina, a política, a militância católica e o ensino. Começou a vida junto à Serra do Cachimbo (Alagoas), onde Zumbi construiu seu Quilombo dos Palmares, e terminou seus dias num consultório médico, também consultório de poesia, no Rio de Janeiro, então capital da República. Esta convivência próxima do mítico e do primitivo com o moderno incipiente, sintomática da condição do próprio país, contribuiu para a formação de uma personalidade literária forte, ganhando em relevo na fase final do poeta, composta pelos seus dois últimos livros: o Livro de sonetos, I949, breve em seus 78 poemas, e sua súmula-testamento poético, a Invenção de Orfeu, de I952, epopéia lírica em dez cantos.

O primeiro destes livros presta-se bem, em sua condensação, à função de mapa de procedimentos formais, eixo de referência para a leitura do extenso e hermético poema final. Nele, afirmava-se uma nova dicção, muito pessoal, calcada na força das imagens, tributária tanto do contato com a revolução técnica operada pelas vanguardas européias deste século (especialmente, os surrealistas), como da continuidade das linhas de força do simbolismo francês do XIX, dicção esta que daria vazão à retomada de todo material poético, muito diversificado, que Jorge de Lima trabalhou ao longo de seu caminho pessoal, estilisticamente bastante acidentado.

Numa primeira incursão crítica à obra do poeta, concentrei-me sobre a imagem como medula e fundamento na lírica final de Jorge de Lima. O resultado foi publicado em $O$ engenheiro noturno: a lírica final de Jorge de Lima (São Paulo: Edusp, I997), livro articulado em três longos capítulos. No primeiro deles, "Jorge de Lima e Murilo Mendes: confluências e divergências", apro- 
ximo, a partir de uma perspectiva comparatista, os dois amigos poetas, que se conheceram num momento chave da carreira de ambos, no cenário da renovação carioca do catolicismo nos anos 30, comungando um certo catolicismo herético, desenvolvido à sombra do orfismo de Ismael Nery e da assimilação de aspectos parciais da poética surrealista. Esta aproximação é pensada em paralelo com um breve retrospecto sobre os mecanismos que levaram a certa naturalização dos procedimentos vanguardistas, especialmente ao rápido abrandamento do poder de choque que, inicialmente, a técnica da montagem trazia, conferindo-lhe o estatuto de recurso expressivo entre outros, a serviço de uma intenção estética unificadora, da construção de uma obra individual, única, que estava bastante distante do contexto de seu surgimento inicial, de dissolução da arte na vida.

Um segundo capítulo, "Fanopéia em Jorge de Lima: a imagem órfica e hermética" recolhe, na obra anterior do poeta, indícios dispersos da importância que a imagem calcada em metáforas absolutas, cifrada e complexa, viria a assumir na obra final,convertida em espelho partido de um mundo cujos valores e sentido não mais são assentes, tampouco comungados coletivamente, mas refundados como protesto individual à totalidade falsa e aprisionadora. Os mecanismos de funcionamento maduro desta nova modalidade de imagem, resistente à interpretação, na poesia de Jorge de Lima foram buscados por meio de uma leitura cerrada dos poemas do Livro dos sonetos, penúltimo volume de poesia do autor.

Por fim, o último capítulo, "O engenheiro noturno e a Invenção de Orfeu" antecipava em esboço algumas das preocupações para as quais me volto aqui, como a possibilidade moderna do poema longo e a intrigante pluralidade de formas e fórmulas poéticas que convivem nesta epopéia peculiar, provocando uma tensão entre a perfeição e acabamento dos poemas breves incrustados nos cantos, pedindo por leituras autotélicas, e sua inevitável sujeição à necessidade narrativa do todo.

$\mathrm{Na}$ Invenção de Orfeu, expressão máxima do estilo final, somam-se à dificuldade primeira da construção imagética ousada e inovadora problemas de natureza bastante diversa. O próprio poema é uma grande indagação sobre a possibilidade moderna do poema longo, contradição nos termos para autores como E.A.Poe e Benedetto Croce. Estão lá, implicadas, uma reflexão sobre a relação entre o mito e a poesia moderna; uma incorporação da história brasileira, poética inclusive, nas citações de episódios, formas e temas tipicamente nacionais; e, não menos importante, a convivência da engenharia poé- 
tica, construção pensada, com a noção de jorro, de expressão intuitiva, habitualmente associadas a Jorge de Lima, um poeta prolífico.

Se, numa primeira aproximação, o poema parece convidar a uma leitura que atente para esta primazia do aspecto imagético, em sua novidade e estranheza, como razão primeira de sua importância, seu interesse não se esgota nesta dimensão. Um poema é um punhado de imagens e um sentimento que as anima, comportando sempre, mesmo que discreta e encoberta, uma narração em embrião. Aqui, neste caso em particular, a narração tem papel muito mais central, visível desde a filiação de gênero sugerida pelo próprio autor (que batizou o poema de épico subjetivo), até as infinitas repercussões, ideológicas e até mesmo políticas, inerentes à matéria poética que aborda. Um simples cotejo de Invenção de Orfeu com a tradição épica brasileira tal como descrita por Sérgio Buarque de Holanda em seus Capítulos de Literatura Colonial pode confirmar esta importância. Roger Bastide e Gilberto Freyre por exemplo dão pistas sobre o tratamento dispensado à convivência colonial com o escravismo em Jorge de Lima ${ }^{\mathrm{I}}$

O esforço de compreensão da obra final de Jorge de Lima deverá, mais cedo ou mais tarde, contemplar um exame meticuloso da mescla de gêneros na Invenção de Orfeu, quando acompanhada pelo fio da narrativa; o que aqui se propõe é uma discussão preliminar de estratégias de aproximação crítica e hipóteses de trabalho que façam justiça à importância do tema. Habitualmente, têm-se contornado a questão recompondo o seu diálogo com a tradição épica ocidental, com os modelos clássicos (Virgílio, Dante, Camões, Tasso), dos quais o poema teria tomado emprestada grande parte de seu arcabouço narrativo. Ora, se esta dimensão é importante, não menos relevante é a tensão que Invenção de Orfeu estabelece com as tentativas locais de realizar a forma épica, com todas as conseqüências para o esboço da idéia de nação no Brasil, em diversos momentos de nossa história.

É preciso não perder de vista a proximidade de Jorge de Lima com a paisagem e história brasileiras, sobretudo nordestina, e seu ajuste de contas com a tradição literária romântica (em que a exaltação da natureza assume papel estratégico no projeto ideológico de construção de um mito de nacionalidade), agora filtrada pelo impulso e olhar modernistas, dessublimatórios. Neste sentido, a Invenção de Orfeu é também uma tentativa de recapturar a matéria vertente da história e da experiência pessoal do poeta, literária inclusive, em tom de anti-epopéia, voltada para a glória anônima, para as "geografias pobres" as "faces perdidas" e para as "flores pétreas" (Invenção
I Leia-se a respeito, o recente artigo de Lúcia Sá, pesquisadora brasileira radicada nos Estados Unidos, tratando da questão pelo ângulo da incorporação da relação entre os colonizadores e os índios brasileiros tal como tratada no poema. Cf. sá, Lúcia. "Invenção de Orfeu e o palimpsesto indígena.' Luso-Brazilian Review, University of Wisconsin, xxxvII, 2000.

2 Cf. Busatto, Luiz. Montagem em Invenção de Orfeu. Rio de Janeiro: Âmbito, 1978. 
de Orfeu, Canto I) das possibilidades caladas e injustiças perpetuadas. Tudo isto, naturalmente, mediado pela dificuldade crucial da forma nova escolhida, a da epopéia lírica.

Ressalte-se que Jorge de Lima foi também romancista e ensaísta, tendo exercido outras modalidades de expressão narrativa, que podem ajudar, e muito, na avaliação do peso relativo que o épico tem na equação da Invenção de Orfeu. Assim, é preciso que nos voltemos também para este lado menos estudado da produção de Jorge de Lima, uma espécie de primo pobre de sua poesia - a obra em prosa - especialmente nos quatro romances que constituem o núcleo da carreira ficcional do autor: O Anjo (I934), Calunga (I935), A mulher obscura (1939) e Guerra dentro do beco (I950). Numa via de mão dupla, Jorge de Lima narrador além de revelar as marcas do criador obsessivo de imagens impactantes, do poeta, esclarece também sua maneira de costurá-las numa estrutura seqüencial, numa história, em que aspectos determinantes da expressão épica (como o elemento mimético) se deixam apanhar com maior transparência. Duas palavras então sobre Jorge de Lima romancista, para exemplificar como o cotejo de percursos pode ser revelador.

\section{Os fios da meada: presença da narrativa na Invenção de Orfeu de Jorge de Li- ma nas pegadas de sua obra romanesca (O Anjo, 1934, Calunga, 1935, e Guerra dentro do beco, 1950).}

Muito do projeto modernista brasileiro continua ainda hoje bastante mal conhecido em sua diversidade, alcance e conseqüências. Reedições recentes de Murilo Mendes e Jorge de Lima nos volumes ambiciosos da Nova Aguilar, por exemplo, ajudam a corrigir o foco da crítica, recompondo o arranjo das peças no tabuleiro da literatura local. Mas, se a prosa peculiar e curiosíssima do poeta mineiro também foi contemplada na edição de I997, a ficção do autor da Invenção de Orfeu ficou de lado, a exemplo do que já ocorrera na primeira edição reunida de sua obra pela Aguilar (1958). Anunciada em dois volumes, poesia e prosa, o segundo, dedicado aos romances, nunca chegou a ser publicado. Só agora, quase quarenta anos depois, a Record os recoloca em circulação, começando por Guerra dentro do beco (I950) e Calunga (I935), seguidos por O Anjo (I934) e A mulher obscura (I939).

Ao contrário do que acontece com Murilo, a ficção de Jorge de Lima sempre foi um pouco desprestigiada em relação aos versos. Em Guerra dentro do 
beco, escrito no início da década de 40, o aspecto desnorteado do protagonista, um pintor limitado engolido pela vida social, corresponde bastante ao caráter errático do romance. Se tenta apanhar o ambiente de discussão, estética e ideológica, que tomava conta do movimento de renovação católica no Rio de Janeiro dos anos 30 (no qual Jorge de Lima tomou parte), o livro não é capaz de individualizar convincentemente os conflitos de seu tempo na personagem central, Júlio Aguiar.

A crise precipitada pelo aborto e a doença da mulher, bibelô burguês que o esteta decadente julgara poder moldar à sua imagem, põe a nu sua fraqueza moral, o enredamento do belicoso beco interior do título. $O$ tom exaltadamente cristão, dostoievskiano em falsete, às voltas com as figuras do salvador desinteressado e do tentador mefistofélico, deforma o retrato em caricatura, num romance de tintas trágicas, enfáticas e desajeitadas.

Já Calunga (1935) ressurge hoje igualmente datado, manifestação ortodoxa da vertente social e engajada do romance brasileiro de 30. Como Júlio Aguiar, Lula Bernardo é um impotente bacharel do litoral que volta às origens, para o interior de Alagoas, atendendo ao chamado da terra, que devora tanto suas boas intenções, quanto o ímpeto reformista.

Confrontado com a culpa de ter abandonado a família, mesmo pouco à vontade na fantasia de homem do campo, Lula instala-se como fazendeiro. Acaba tragado pelas engrenagens da política local, personificadas nas maldades frias do coronel vizinho, escorado no clientelismo e na jagunçagem, numa reencenação fatalista do destino humano para a queda. Mais acabado estruturalmente do que a Guerra dentro do beco, Calunga não alcança o vôo que Jorge de Lima alça a partir do mesmo material simbólico nos poemas de inspiração regionalista ${ }^{3}$.

A disposição protéica da forma em seu percurso poético, típica da fase heróica do Modernismo, também se reflete nos romances, nas suas idas e vindas estéticas e ideológicas, próprias do momento de efervescência cultural e da multiplicação de tentativas de explicar o país, contemporâneas ao seu amadurecimento literário.

Prismatizada por este empenho analítico em desvendar o Brasil, a incorporação dos procedimentos artísticos das vanguardas européias do começo do século já aparece no romance de I934, O Anjo, o mais interessante dentre os romances que deixou. Seu caráter híbrido antecipa temas e combina estratégias narrativas que Jorge de Lima desenvolveria futuramente. Assim, as vertentes social e interiorizante que marcaram a ficção brasileira em 30
3 Sobre Novos poemas e Poemas negros, ver $O \mathrm{en}$ genheiro noturno: a lírica final de Jorge de Lima. Op. cit., p.24ss. 
assumiriam aspecto próprio neste livro, de laivos surreais e filiado ao experimentalismo modernista: teriam sido incorporados como elementos a serviço do todo, mais esboçados do que eleitos sem reservas como modelos e soluções estéticas ideais.

Espelhado em um protagonista alegoricamente denominado Herói, o romancista trabalha a divisão da personagem entre o mundo da origem e da infância, onde se justapõem a miséria social e a riqueza simbólica da província, e o mundo vertiginoso da cidade, do anonimato, da multidão, ameaçador, mas também atraente para o boêmio e esteta in nuce. A narrativa, entrecortada de prosa poética, valendo-se da técnica da montagem, tem seu toque surreal no companheiro de peripécias de Herói, o Anjo que dá nome ao texto e, paradoxalmente, humaniza-se em percurso contrário, em forma de quiasma, ao do protagonista, Herói, que aos poucos vai se descolando das obrigações cotidianas, eterizando-se.

As rupturas na organização do espaço-tempo, o onirismo, o tema moderno por excelência do artista em crise, fascinado e horrorizado pela cidade, aproximam $O$ Anjo do universo do surrealismo. Bem ou mal resolvida, tratase de uma absorção crítica e parcial das técnicas surrealistas, adaptadas às necessidades expressivas de um grupo de artistas brasileiros de preocupações espirituais peculiares, que combinariam catolicismo e arte, enxergando no ato da criação estética um simulacro da criação divina, no poeta um pequeno demiurgo, sacralizando o mundo e a natureza.

O parentesco destas idéias com o Essencialismo do poeta bissexto, pintor e visionário Ismael Nery é evidente. As leituras do neotomismo de Jacques Maritain e a convivência com Georges Bernanos também entram neste cadinho pessoal que enforma o catolicismo do poeta. Talvez aí esteja um dos maiores interesses da produção ficcional de Jorge de Lima: falha como seja, denuncia estações intermediárias para as suas aparentemente abruptas guinadas estéticas, aponta continuidades onde tudo lembra saltos. Mais, acaba por apontar uma dificuldade de formalização que se reproduz em sua obra poética final, dificuldade que não aparece por defeito ou falha de seu criador, mas que corresponde à complexidade da charada formal que se propõe a resolver, especificamente nossa, brasileira.

William Cereja sustenta que a afirmação de certo universo pessoal, invariável, se deu desde o início deste percurso de narrador que Jorge de Lima desenvolveu, paralelo ao do poeta que encerrou sua produção com uma for$\mathrm{ma}$, o épico, em que o narrativo tem papel central. ${ }^{4} \mathrm{O}$ apego ao imaginário 
clássico, a valorização dos mitos fundamentais do cristianismo (em especial, o da queda), a preferência por protagonistas que espelhem a condição moderna do artista seriam traços essenciais do perfil jorgeano enquanto romancista; a opção religiosa do autor, reconvertido ao catolicismo no momento em que a Igreja brasileira passava por um processo de renovação, guinando em direção a um reformismo e intervencionismo social, transpassa sua evolução, diz William, e tem papel determinante no aspecto final dos romances.

Para evitar os rótulos redutores, como a filiação sem mais de Jorge de Lima ao grupo católico carioca, William vê-se obrigado a trabalhar em diversas frentes. Trata-se de convencer o leitor de que os romances não são mal-realizados, colcha de retalhos de procedimentos, ecletismo irresponsável; ao mesmo tempo, de demonstrar a atualidade das preocupações estéticas do autor, colocando em cena a própria figura do criador, impotente, falível e consciente desta falibilidade, além de contextualizar a tendência à combinação de modelos dificilmente reconciliáveis que caracteriza a ficção de Jorge de Lima; em suma, de evidenciar uma certa coerência que permita falar em projeto artístico e unifique num percurso inteligível os quatro romances, apesar de sua diversidade formal.

O caráter composto das experiências ficcionais de Jorge de Lima é respeitado pelo trabalho de William, que tem em seu ponto de partida - O Anjo, de I934 - o objeto ideal. Mas é justamente o elemento ideológico (a opção católica) que sustenta a tese central do trabalho de William. Na leitura dos demais romances, explicando o sucesso ou o insucesso da forma. O espiritual acaba por engolir o ético (o social em Calunga justificaria sua filiação ao romance regionalista de 30 , não fosse a leitura alegórica e religiosa que, na visão de William, prevalece) e o estético (o surrealismo n'O Anjo é mais uma roupagem do drama adâmico que Jorge de Lima revive obsessivamente como exemplo universal e invariável da condição humana). Na argumentação de William, a crítica tem lido erroneamente a obra ficcional jorgeana por não conceder suficiente atenção a este componente determinante que diferencia sua produção das correntes hegemônicas na época, tornando-a irrealizada de acordo com parâmetros inadequados para julgá-la, submetendo-a a uma patrulha ideológica extemporânea.

A ênfase analítica do trabalho, de clara preocupação didática, minúcia e rigor no tratamento das diversas correntes envolvidas na formulação da fisionomia específica da prosa de Jorge de Lima, acaba resultando num paradoxo. A consciência do caráter híbrido do objeto leva William a ocupar-se de
4 Cf. CEREJA, William

R. O Anjo caído: fisionomia da ficção de Jorge de Lima. São Paulo, I994. Dissertação (Mestrado em Teoria Literária e Literatura Comparada) - FFLCHUSP. 
cada uma das forças em jogo na prosa do autor separadamente, escolhendo um método de trabalho que o coloca refém do estabelecimento de correspondências biunívocas. $O$ paradoxo é que acabam se perdendo nuances que o trabalho afirma presentes; a interpenetração e cruzamento de correntes dilui-se em parte na descoberta dualista das semelhanças e diferenças, armadilha que a própria seriedade do pesquisador preparou. A timidez em propor uma síntese talvez impeça o trabalho de dar um salto interpretativo e avaliatório. No afã de respeitar ao máximo o rigor, corre-se o risco de perderse na extrema universalidade, na redução ao máximo denominador comum, ele próprio mínimo.

Quando percebe invariáveis em Calunga, n'A mulher obscura e em Guerra dentro do beco, como a repetição do tema da queda e da falibilidade orgulhosa resumindo o destino humano, ou a busca de um ideal feminino que concilie sensualidade e misticismo, traços também marcantes da produção poética do autor, William está em terreno seguro: identifica o material simbólico fundamental à ficção de Jorge de Lima, ao lado do universo da infância nordestina. Dá-se o mesmo quando aponta a constância com que o tema do criador angustiado reaparece nos quatro romances, apesar das diferenças de gênero, ambientação e estilo. E não apenas na ficção: o trabalho mostra que passagens em prosa poética foram incluídos por Jorge em livros de poesia, numa prova clara das ligações entre as diversas modalidades de escrita praticadas por ele.

O problema aparece quando passa a ler nos quatro livros que toma por objeto de análise como o Livro e cede, ainda que parcialmente, à tentação de ler literatura como testemunho de doutrinas. Neste ponto, a volta constante a arquétipos da tradição cristã-ocidental deixa de ser tratado como um recurso literário à experiência humana sedimentada em mitos - topói que têm história literária própria e lógica interna ao universo das narrativas - e reverte ao mundo das idéias, das angústias espirituais e políticas que estão por trás do homem público que foi o autor.

Do ponto de vista da história cultural, trata-se de um movimento da maior relevância e William reconstrói o ambiente de acirramento no debate ideológico entre esquerda e direita, acompanhando as flutuações do grupo católico, como um todo - e as de Jorge de Lima, em particular - com extrema fidelidade. Mas os méritos e deméritos próprios do ficcionista, assinalados pela análise empreendida, aparecem atenuados pelo traço que William descobriu como o mais forte de sua fisionomia: a opção militantemente cristã, 
que subjuga os modelos e molda a estrutura segundo as suas necessidades. Ainda assim, seu trabalho dá um importante passo para a compreensão do Jorge de Lima romancista, essencial para quem pretende aproximar narrador e poeta em seu poema testamento, a Invenção de Orfeu.

$\mathrm{Na}$ aproximação do poeta - servindo-se de uma forma essencialmente marcada pela narrativa, a epopéia, ainda que em versão moderna e problemática - e do romancista - para o qual as imagens tinham apelo construtivo inegável - tira-se a lição de que a incorporação de motivos temáticos e formais da história brasileira na Invenção de Orfeu não pode ser dissolvida em mera análise conteudística. A avaliação de sua importância só cabe dentro da grande charada formal e crítica que o poema final de Jorge de Lima tem provado ser ao longo dos últimos quase cinqüenta anos, desafio que ainda persiste e para o qual o presente projeto se encaminha.

\section{Dificuldades da forma: o local e o cosmopolita na arte moderna brasileira}

Na discussão do sentido histórico que recobre os problemas técnicos enfrentados por grandes nomes da arte brasileira, Rodrigo Naves encontrou um par de conceitos que descrevem bem o horizonte de equilíbrio precário entre a forma lograda e a irresolução formal que circunscreve boa parte da produção plástica nacional mais representativa, instabilidade que não se aplica apenas a ela: uma fina linha separa o estágio de dificuldade da forma, da forma difícil, título de seu livro.s

Naves aborda a pedregosa estrada que leva à constituição da brasilidade em obras tão díspares quanto as de Guignard, Volpi, Lasar Segall e Amílcar de Castro. Divididas entre o apelo das soluções formais tomadas por empréstimo à vanguarda européia, soluções que apontam para o abandono da vocação ilusionista da arte naturalista, e a necessidade de dar vazão a uma matéria local clamando por expressão, as soluções híbridas adotadas por cada um deles são examinadas em profundidade. No caso de Guignard, as paisagens lavadas das montanhas mineiras sugerem tempo suspenso e eternidade. Apesar de aparentemente desrealizadas, em consonância com a tendência da arte moderna dos grandes centros mundiais, encontram-se incrustadas de signos muito marcadamente locais, tais como as bandeiras de São João, os balōes, os folguedos populares, as igrejinhas com cara de festa.

Para os leitores da Invenção de Orfeu, é bastante sugestiva a ênfase na di-
5 NAves, Rodrigo. $A$

Forma dificil, São Paulo:

Ática, 1996 . 
6 Sobre a relação

peculiar do poeta Jorge

de Lima com as van-

guardas européias, ver

O engenheiro noturno: a

lírica final de Jorge de

Lima. Op. cit., p.48ss. ficuldade de compor a ampla escala do olhar, tendendo à transcendência, abrindo-se para uma dimensão cósmica, de diluição de contornos específicos, esfumando a realidade e sugerindo uma abstração da paisagem, com a atenção detalhista, voltada para a apreensão das particularidades locais e historicamente ancorada na experiência brasileira. Como acontece na obra de Jorge de Lima, também aqui um olhar recoberto de afetividade revela uma tendência à neutralização das relações conflitivas do mundo do trabalho, cujo potencial explosivo fica hibernando no universo de Guignard, esconjurado por certa fixação em elementos imemoriais, arcaicos da nossa organização social, fundada no favor e no compadrio, e economizando sua contaminação pela modernidade problemática (presente, contudo, pela incorporação de traços técnicos tomados às vanguardas). A dificuldade da forma deriva desta tensão mal resolvida, que paradoxalmente é a responsável maior pela sua singularidade e contribuição pessoal, marca indiscutível e inconfundível da personalidade do artista, livrando-o do risco da mera assimilação atrasada de modelos europeus, da filiação epigonal e sem lastro histórico que a justificasse. ${ }^{6}$

Segundo Naves, a pintura de Guignard não alcançou o salto para a "forma difícil" estágio em que as contradições não aparecem como obstáculo à realização estética integral, mas são internalizadas, tornando-se vetores estruturais da própria recusa de compactuar e deixar-se assimilar da obra, crítica e resistente. Transposta à poesia de Jorge de Lima, a questão se reproduz: teria o poeta materializado na Invenção de Orfeu a "forma difícil"? Estaríamos às voltas com um fracasso parcial, decorrente das dificuldades de realizar um poema de fôlego épico na modernidade ou, ao contrário, com uma rara riqueza formal, localizada precisamente na dificuldade de um poema cuja leitura arriscada se paga inteiramente?

O caminho mais curto para o que há de brasileiro em Jorge de Lima certamente passa pelas suas contradições ideológicas, sua expressão ensaística e artística manifesta, sua militância regionalista, pela apropriação que faz de ritmos e melodias populares, nos poemas negros, ou de motivos da épica colonial brasileira. Em seu poema final, cuja vocação é a de súmula de percurso, não faltará material que alimente esta discussão, presa ao domínio do temático. Ao contrário de sua obra narrativa, cuja leitura parece sugerir, para falarmos como Naves, que estamos efetivamente confrontados por um bloqueio formal, pela incapacidade de encontrar solução a contento, a Invenção de Orfeu parece ser o lugar do salto qualitativo em Jorge de Lima: em sua tentativa de conjugar a forma lírica e a forma épica talvez esteja a verdadeira forma, difícil, da epopéia moderna e brasileira, tingida das cores da 
subjetividade partida, expressa em constelações de imagens complexas. A charada crítica talvez encontre nesta hipótese, se não o caminho de decifração final, uma possibilidade de recolocar os termos da equação de maneira mais reveladora.

Fábio de Souza Andrade é professor de Teoria Literária e Literatura Comparada da Universidade de São Paulo e autor de $O$ Engenheiro Noturno: a lírica final de Jorge de Lima [Edusp, I997] e Samuel Beckett: o silêncio possível [Ateliê, 200I]. 


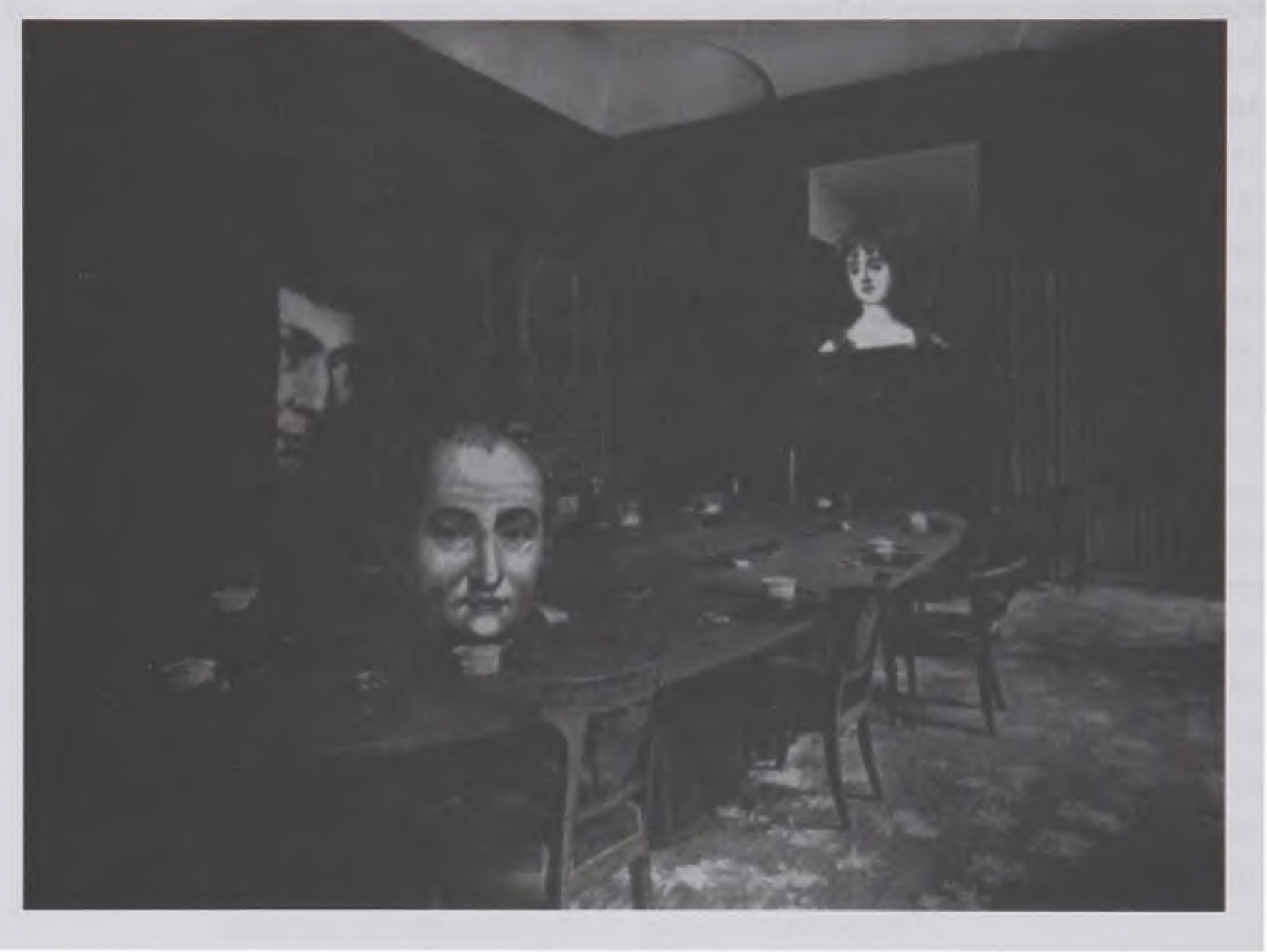

